\title{
Rhodococcus equi isolation from sputum of patients with suspected tuberculosis
}

\author{
Paulo da Silva ${ }^{1,2}$, Marcelo Miyata1, Daisy Nakamura Sato ${ }^{2}$, Adolfo Carlos Barreto Santos ${ }^{1}$, \\ Natália Helena Mendes ${ }^{1}$, Clarice Queico Fujimura Leite ${ }^{1 /+}$ \\ ${ }^{1}$ Faculdade de Ciências Farmacêuticas, Universidade Estadual Paulista, Araraquara, SP, Brasil '2Laboratório de Ribeirão Preto, Instituto \\ Adolfo Lutz, Ribeirão Preto, SP, Brasil
}

Rhodococcus equi has emerged as an opportunistic pathogen associated with pulmonary, invasive or systemic infections in immunocompromised patients. We report the identification of $51 \mathrm{R}$. equi isolates found in sputum samples of 546 individuals suspected to have pulmonary tuberculosis in two Public Health Hospital Units in Brazil. The epidemiology of R. equi infection as well as the phenotypic identification and drug susceptibility profile of isolates are described in this paper.

Key words: Rhodococcus equi - identification - tuberculosis - antimicrobial profile - epidemiology

The genus Rhodococcus belongs to the group of nocardioform, Gram-positive rods containing mycolic acids in the cell wall; this group also includes the genera $M y$ cobacterium, Nocardia, Corynebacterium, Dietzia, Gordonia, Millisia, Segniliparus, Skermania, Tsukamurella and Williamsia (Soddell et al. 2006a, b, Tsitko et al. 2006). The genus Rhodococcus was discovered by Zopf in 1891 (Goodfellow \& Alderson 1977) and comprises 30 species, of which Rhodococcus equi is considered the most opportunistic pathogen in mammals, including humans (Meijer $\&$ Prescott 2004). The first case of human infection was reported in 1967 in a patient presenting with a pulmonary abscess. The two first cases that occurred in Brazil were reported by Severo et al. (2001). However, with the AIDS epidemic, the number of patients infected by $R$. equi has grown (Roda et al. 2009). $R$. equi also causes infection in patients with lymphoma, chronic renal failure, alcoholism, lung cancer, leukaemia, diabetes mellitus and other immunodeficient syndromes. Some cases have been reported in which the infection can also occur in immunocompetent hosts (von Bargen \& Haas 2009).

When incubated aerobically at $37^{\circ} \mathrm{C}, R$. equi grows efficiently in the majority of nonselective culture media, including media used in mycobacteria isolation and produces irregular, smooth and mucoid colonies that turn a shade of salmon pink to yellow after a week of growth (Prescott 1991). R. equi appears coccoid on stained smears of clinical specimens, especially purulent material and tissue (obtained by biopsy, during surgery and upon autopsy). However, long rods have been reported in clinical specimens isolated from blood, sputum and bronchial lavage fluid (von Bargen \& Haas 2009). Colony morphology and acid-fast staining are characteristic fea-

Financial support: FAPESP, CNPq

+ Corresponding author: 1eitecqf@fcfar.unesp.br

Received 20 October 2009

Accepted 25 February 2010 tures in the initial identification of different nocardioform genera (Christopher \& Bruno 2002). In general, R. equi is biochemically non-reactive, has no proteolytic activity and fails to oxidize or ferment carbohydrates, with the exception of glucose, which is oxidized by $R$. equi in 14 days. $R$. equi is strictly aerobic, catalase positive, oxidase negative and mostly urease positive. $R$. equi produces soluble "equi factors" that are associated with phospholipase and cholesterol oxidase activity and interact with phospholipase D of Listeria ivanovii to induce complete haemolysis of sheep erythrocytes (Prescott 1991).

The Laboratory of Mycobacteriology at the Adolfo Lutz Institute in Ribeirão Preto (SP, Brazil) has frequently isolated partial acid-fast bacteria from sputum of patients suspected to have pulmonary tuberculosis. Considering the emerging clinical importance of $R$. equi, our goal was to identify the 51 partial acid-fast bacteria isolated from sputum, to determine the antimicrobial profiles of these isolates and to analyse the epidemiological characteristics of patients with $R$. equi infection.

\section{PATIENTS, MATERIALS AND METHODS}

Clinical samples - Sputum samples (duplicates/triplicates) were obtained from 546 patients suspected to have pulmonary tuberculosis in Public Health Hospital Units in Ribeirão Preto and the surrounding region. The samples were analysed by the Laboratory of Mycobacteriology at the Adolfo Lutz Institute in Ribeirão Preto.

R. equi isolation and identification - After testing for acid-fast bacilli (AFB), samples from 296 patients showed the presence of AFB; in 60 patients, partial AFB or coccobacilli, suggestive of Rhodococcus spp, were isolated. The AFB samples were cultured using the automated $\mathrm{MB} / \mathrm{BacT}$ system (bioMérieux) and subjected to mycobacteria identification by phenotypic methods and Accuprobe ${ }^{\circledR}$ (GenProbe). The 60 AFPB were cultured on Müeller Hinton agar (MH) plates and using the automated $\mathrm{MB} / \mathrm{BacT}$ system (bioMérieux) to verify the absence of Mycobacterium spp. Isolated colonies were transferred to $\mathrm{MH}$ agar slants in tubes. The identifica- 
tion of $R$. equi was based on microscopic observation of bacteria subjected to Gram's and Ziehl-Neelsen staining (Ballows et al. 1991) and phenotypic biochemical tests described in the Manual of Systematic and Clinic Microbiology (Ballows et al. 1991, Holt et al. 1994, Murray et al. 1999, Koneman et al. 2000, Mac Faddin 2000). Gordon's base culture medium was used for acid production in carbohydrate tests (McNeil \& Brown 1994). The CAMP test was performed as described by Bille and Doyle (1991), using L. ivanovii ATCC 19119 and R. equi ATCC 6939 as standard strains.

Susceptibility tests - The disk-diffusion method was performed as recommended in the Clinical and Laboratory Standard Institute/National Committee and Clinical Laboratory Standards guidelines. In this method, 28 antimicrobial agents were used (results of Staphylococcus $\mathrm{sp}$. were used as the basis for data interpretation) (CLSI/ NCCLS 2004) and $R$. equi ATCC 6939, Enterococcus fecalis ATCC 29212 and Staphylococcus aureus ATCC 25923 served as the reference strains.

Epidemiological investigation - The available patient data, such as gender, age and immunosuppressive condition, were utilized for epidemiological investigation.

\section{RESULTS}

Sixty patient samples out of a total of 546 patients had evidence of Rhodococcus spp isolates and among these, 51 were identified as $R$. equi based on the results of the phenotypic tests presented in Table I. All of the 51 isolates were catalase positive, oxidase negative and failed to oxidize or to ferment carbohydrates or alcohols. These isolates produced equi factors (CAMP test) and lipase but not gelatinase, esculinase, $\mathrm{H}_{2} \mathrm{~S}$ or indole and they did not use citrate or malonate. For nitrate reductase, urease and hippurate reduction, the 51 isolates showed variable results. There was $100 \%$ similarity between the 51 isolates and R. equi ATCC 6939, the standard strain. Nine isolates could not be identified as $R$. equi because the CAMP test was negative, despite the similarity of results in all other tests and in comparison to the standard strain.

The analysis of epidemiological data showed that, from a total of 51 patients infected by R. equi, 37 (72.5\%) were male and $14(27.4 \%)$ were female. The age range most affected was between $31-50$ years, comprising $60.8 \%$ of patients. There were no cases of childhood infection. The youngest patient was 17 years old and the oldest was 69 years old (Figure). All patients showed some degree of immunosuppression, such as through infection with HIV, chronic alcoholism, drug use or transplant surgery.

Twenty-eight antimicrobial agents were tested against the $51 R$. equi isolates by the disk-diffusion method. The sensitivity profile can be seen in Table II. The aminoglycosides (amikacin and gentamicin), the tetracycline (minocycline) and the glycopeptides (teicoplamin and vancomycin) were $100 \%$ effective. The macrolides (azithromycin and clarithromycin) were also $100 \%$ effective, with the exception of erythromycin, for which one isolate showed intermediate sensitivity ( $98.04 \%$ effective). The $\beta$-lactam agents alone showed poor activity $(49.02 \%$ for cefoxitin, $45.10 \%$ for cefepime, $23.53 \%$ for cefotaxime, $19.60 \%$ for
TABLE I

Phenotypic identification of Rhodococcus equi

\begin{tabular}{|c|c|c|c|}
\hline \multirow[b]{2}{*}{$\begin{array}{l}\text { Phenotypic } \\
\text { characteristics of } R . \text { equi }\end{array}$} & \multicolumn{3}{|c|}{$\begin{array}{c}\text { Phenotypic characteristics } \\
\text { of } 51 \text { isolates }\end{array}$} \\
\hline & $\begin{array}{l}\text { Reaction }^{a} \\
\%\end{array}$ & $\begin{array}{c}\text { Positives } \\
\mathrm{n}\end{array}$ & $\begin{array}{c}\text { Result } \\
\%\end{array}$ \\
\hline Catalase & $100(+)$ & 51 & $100(+)$ \\
\hline Oxidase & $1-5(+)$ & 0 & $100(-)$ \\
\hline Motility & $100(-)$ & 0 & $100(-)$ \\
\hline Obligate aerobe & $100(+)$ & 51 & $100(+)$ \\
\hline Glucose fermentation & $100(-)$ & 0 & $100(-)$ \\
\hline Glucose oxidation & $100(+)$ & 51 & $100(+)$ \\
\hline Sole carbon source ${ }^{b}$ & $100(-)$ & 0 & $100(-)$ \\
\hline equi factor (CAMP test) & $100(+)$ & 51 & $100(+)$ \\
\hline Gelatinase & $100(-)$ & 0 & $100(-)$ \\
\hline Indol & $100(-)$ & 0 & $100(-)$ \\
\hline $\mathrm{H}_{2} \mathrm{~S}$ & $32(+)$ & 0 & $100(-)$ \\
\hline Urease & $95(+)$ & 45 & $88(+)$ \\
\hline Nitrate reduction & $88(+)$ & 50 & $98(+)$ \\
\hline Lipase & $100(+)$ & 51 & $100(+)$ \\
\hline DNase & $100(-)$ & 0 & $100(-)$ \\
\hline Lecithinase & $100(-)$ & 0 & $100(-)$ \\
\hline Hippurate hydrolysis & $1(+)$ & 06 & $88(-)$ \\
\hline Esculin hydrolysis & $4(+)$ & 0 & $100(-)$ \\
\hline Adenine hydrolysis & $100(+)$ & 51 & $100(+)$ \\
\hline Casein hydrolysis & $100(-)$ & 0 & $100(-)$ \\
\hline Hypoxanthine hydrolysis & $100(-)$ & 0 & $100(-)$ \\
\hline Tyrosine hydrolysis & $100(-)$ & 0 & $100(-)$ \\
\hline Xanthine hydrolysis & $100(-)$ & 0 & $100(-)$ \\
\hline
\end{tabular}

$a$ : adapted from Prescott 1991, McNeil and Brown 1994 and Christopher and Bruno 2002; $b$ : all isolates failed to use acetate, citrate or malonate as sole carbon source, or produce acid from adonitol, arabinose, cellobiose, erythritol, fructose, galactose, glycerol, inositol, maltose, mannitol, mannose, melibiose, raffinose, rhamnose, sucrose, salicin, sorbitol, starch and xylose; +: positive reaction; -: negative reaction.

cephalothin, $13.73 \%$ for cefazolin, $7.84 \%$ for ampicillin, $5.88 \%$ for penicillin and $1.96 \%$ for oxacillin) but when associated with a $\beta$-lactamase inhibitor, the activity rose significantly $(98.04 \%$ for amoxicillin and clavulanate). Imipenem $(98.04 \%)$ and ceftriaxone $(80.39 \%)$ were the most effective $\beta$-lactam agents. Other antimicrobial agents that showed low activity were clindamycin and sulfamethoxazole + thrimethoprim, in which $90.20 \%$ and $58.84 \%$ of the strains were resistant, respectively. The quinolones, levofloxacin $(96.08 \%)$, ciprofloxacin $(92.16 \%)$ and norfloxacin $(90.20 \%)$, were very effective, as were rifampin $(98.04 \%)$, doxycycline $(96 \%)$, chloramphenicol $(84.31 \%)$ and tetracycline $(78.43 \%)$.

\section{DISCUSSION}

Among the 546 sputum samples from individuals suspected to have pulmonary tuberculosis, it was found that 406 patient samples effectively gave acid-fast or partial acid-fast positive results. Mycobacterium tuberculosis and nontuberculous mycobacteria were isolated 


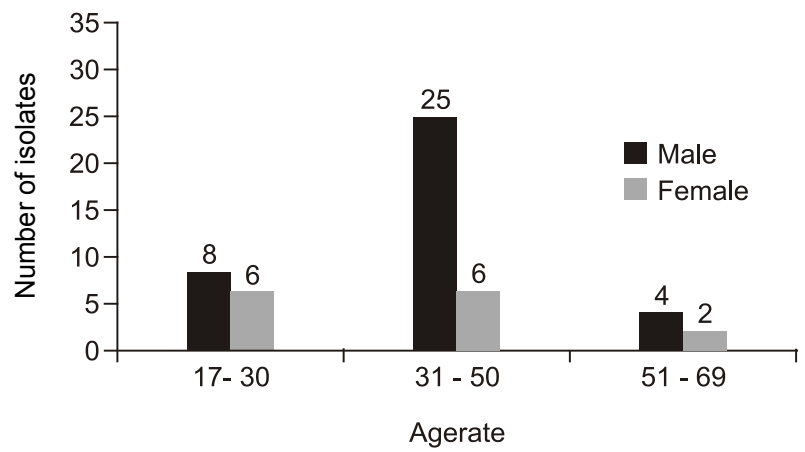

Age and sex distribution of 51 isolates phenotypically characterized as Rhodococcus equi from sputum.

from $67.5 \%(274 / 406)$ and $17.7 \%(72 / 406)$ of the patients, respectively. $R$. equi was identified as the single agent in $12.6 \%(51 / 406)$ of patients. Another nine isolates (2.2\%) gave negative CAMP test results and were considered only to be Rhodococcus spp, although these isolates showed similar results as the standard strain in all other biochemical tests. According to Bille and Doyle (1991) and Prescott (1991), R. equi isolates with a negative equi factor have been described. In spite of the general consensus that human infections with $R$. equi are rare, our results indicated that infection is not so infrequent. Corti et al. (2009) and Martin et al. (2007) suggested that in patients with $M$. tuberculosis/HIV co-infection, respiratory pathogens such as $R$. equi should also be considered. Due to the similarity of the clinical symptoms of rhodococcosis and tuberculosis (Tsitko et al. 2006), as well as the high prevalence of tuberculosis in the population and the partial acid-fastness of $R$. equi, a mistaken diagnosis can easily be made in the laboratory and in medical practice.

The epidemiological data analysis showed that $R$. equi was isolated four times more often in male patients, whose predominant $(60.8 \%)$ age range was from $31-50$ years. A male predominance of 3:1 for pulmonary rhodococcosis was also observed by Kedlaya et al. (2001). HIV infection is one of the main factors predisposing patients to $R$. equi infection (Roda et al. 2009) and normally, the incidence of HIV is higher among males, which explains the predominance of $R$. equi strains in males. In our study, all 51 patients infected with $R$. equi were also coinfected with HIV. Torres-Tortosa et al. (2003) assessed $R$. equi infection in 67 patients co-infected with HIV. Fifty-five patients were male with ages varying between 25-37 years. These authors also found that most (52.2\%) of these bacterial isolates came from sputum.

Treatment of $R$. equi infection must be based on the results of antimicrobial susceptibility tests because there is no standard drug regimen for $R$. equi infection in humans (Roda et al. 2009) and the emergence of some strains resistant to various antibiotics has been reported within the last 10 years (Buckley et al. 2007). R. equi isolates in our study showed resistance to $\beta$-lactam agents, in agreement with the results described by Roda et al. (2009). When $\beta$-lactam agents were combined with a
TABLE II

Susceptibility test results in disk-diffusion test with 28 antimicrobial agents against 51 Rhodococcus equi isolates ${ }^{a}$

\begin{tabular}{|c|c|c|c|}
\hline \multirow{3}{*}{$\begin{array}{l}\text { Antimicrobial agents } \\
\text { (concentration) }\end{array}$} & \multirow{2}{*}{\multicolumn{3}{|c|}{$\begin{array}{l}\text { Isolates/isolates tested } \\
\mathrm{n}(\%) \\
\text { Interpretation categories }\end{array}$}} \\
\hline & & & \\
\hline & Sensitive & Intermediate & Resistant \\
\hline \multicolumn{4}{|l|}{ Aminoglycosides } \\
\hline AMI $(30 \mu \mathrm{g})$ & $51(100)$ & - & - \\
\hline GEN $(10 \mu \mathrm{g})$ & $51(100)$ & - & - \\
\hline \multicolumn{4}{|l|}{$\beta$-lactams } \\
\hline AMC $(30 \mu \mathrm{g})$ & $50(98)$ & - & $01(20)$ \\
\hline AMP $(10 \mu \mathrm{g})$ & $04(7.8)$ & - & $47(92.2)$ \\
\hline CFL $(30 \mu \mathrm{g})$ & $10(19.6)$ & $01(2)$ & $40(78.4)$ \\
\hline CFZ $(30 \mu \mathrm{g})$ & 07 (13.7) & $01(2)$ & $43(84.3)$ \\
\hline CRO $(30 \mu \mathrm{g})$ & $41(80.4)$ & $03(5.9)$ & $07(13.7)$ \\
\hline CFO $(30 \mu \mathrm{g})$ & 25 (49) & $11(21.6)$ & $15(29.4)$ \\
\hline CTX $(30 \mu \mathrm{g})$ & $12(23.5)$ & $01(2)$ & $38(74.5)$ \\
\hline CРM $(30 \mu \mathrm{g})$ & $23(45.1)$ & $06(11.8)$ & $22(43.1)$ \\
\hline IPM $(10 \mu \mathrm{g})$ & $50(98)$ & - & $01(2)$ \\
\hline OXA $(5 \mu \mathrm{g})$ & $01(2)$ & - & $50(98)$ \\
\hline PEN (10UI) & $03(5.9)$ & - & $48(94.1)$ \\
\hline \multicolumn{4}{|l|}{ Chloramphenicol } \\
\hline CLO $(30 \mu \mathrm{g})$ & $43(84.3)$ & $02(4)$ & $06(11.7)$ \\
\hline Glycopeptides & - & - & - \\
\hline TEC $(30 \mu \mathrm{g})$ & $51(100)$ & - & - \\
\hline VAN $(30 \mu \mathrm{g})$ & $51(100)$ & - & - \\
\hline \multicolumn{4}{|l|}{ Lincosamide } \\
\hline CLI $(2 \mu \mathrm{g})$ & $01(2)$ & $04(7.8)$ & $46(90.2)$ \\
\hline Macrolides & - & - & - \\
\hline AZI $(15 \mu \mathrm{g})$ & $51(100)$ & - & - \\
\hline CLA $(15 \mu \mathrm{g})$ & $51(100)$ & - & - \\
\hline ERI $(15 \mu \mathrm{g})$ & $50(98)$ & $01(2)$ & - \\
\hline \multicolumn{4}{|l|}{ Quinolones } \\
\hline CIP $(5 \mu \mathrm{g})$ & $47(92.1)$ & $03(5.9)$ & $01(20)$ \\
\hline LVX $(5 \mu \mathrm{g})$ & $49(96)$ & $01(2)$ & $01(2)$ \\
\hline NOR $(10 \mu \mathrm{g})$ & $46(90.2)$ & $01(2)$ & $04(7.8)$ \\
\hline Rifampin & - & - & - \\
\hline RIF $(5 \mu g)$ & $50(98)$ & - & $01(2)$ \\
\hline \multicolumn{4}{|l|}{ Sulfa + trimethoprim } \\
\hline SMT $(25 \mu \mathrm{g})$ & $21(41.2)$ & - & $30(58.8)$ \\
\hline Tetracyclines & - & - & - \\
\hline TET $(30 \mu \mathrm{g})$ & $40(78.4)$ & $08(15.7)$ & $03(5.9)$ \\
\hline DOX $(30 \mu \mathrm{g})$ & $49(96)$ & $01(2)$ & $01(2)$ \\
\hline MIN $(30 \mu \mathrm{g})$ & $51(100)$ & - & - \\
\hline
\end{tabular}

$a$ : the Interpretative Patterns of Halo Inhibition Diameters were those determined for Staphylococcus sp., in agreement with Clinical and Laboratory Standards Institute, Performance Standards for Antimicrobial Susceptibility Testing, Fifteenth Informational Supplement, document M100-S15 (ISBN 1-56238-556-9. 2005); AMC: amoxicillin + clavulanate; AMI: amikacin. AMP: ampicillin; AZI: azithromycin; CFL: cephalothin; CFO: cefoxitin; CFZ: cefazolin; CIP: ciprofloxacin; CLA: clarithromycin; CLI: clindamycin; CLO: chloramphenicol; CPM: cefepime; CRO: ceftriaxone; CTX: cefotaxime; DOX: doxycycline; ERI: erythromycin; GEN: gentamicin; IPM: imipenem; LVX: levofloxacin; MIN: minocycline; NOR: norfloxacin; OXA: oxacillin; PEN: penicillin G; RIF: rifampin; SMT: sulfamethoxazole + Trimethoprim; TEC: teicoplanin; TET: tetracycline; VAN: vancomycin. 
beta-lactamase inhibitor, the activity was significantly increased $(98.04 \%$ for amoxicillin-clavulanate), confirming the correlation of $\beta$-lactamase enzyme production and resistance.

Because $R$. equi is an intracellular bacteria, the infection can be treated with macrolides, such as erythromycin and rifampicin (Heidmann et al. 2006, Buckley et al. 2007). The macrolides tested in our study, azithromycin and clarithromycin, were $100 \%$ effective, while erythromycin was $98 \%$ effective against the $R$. equi isolates. The quinolones were very effective against $R$. equi, with sensitivity similar to that against $M$. tuberculosis clinical isolates (Ginsburg et al. 2003). Rifampin, a first-line drug for tuberculosis control, was also effective in $98.04 \%$ of isolates. Torres-Tortosa et al. (2003) reported that in 55 patients infected with $R$. equi, the most effective antibiotics were vancomycin, amikacin, rifampin, imipenem, ciprofloxacin and erythromycin. The effectiveness of these antibiotics was confirmed in our 51 isolates.

$R$. equi infection in humans is an underidentified disease and can be confused with tuberculosis or other granulomatous pathologies. Our intention is to alert health professionals about the importance of investigating suspected pulmonary pathologies for potential $R$. equi infection, especially in immunocompromised patients with cavitary lesions.

\section{REFERENCES}

Balows A, Hausler Jr WJ, Herrmann KL, Isenberg HD, Shadomy HJ 1991. Manual of clinical microbiology, 5th ed., ASM Press, Washington DC, 1364 pp.

Bille J, Doyle MP 1991. Listeria and Erysipelothrix. In A Balows, WJ Hausler Jr, KL Herrmann, HD Isenberg, HJ Shadomy, Manual of clinical microbiology, 5th ed., ASM Press, Washington DC, p. $287-295$.

Buckley T, McManamon E, Stanbridge S 2007. Resistance studies of erythromycin and rifampin for Rhodococcus equi over a 10-year period. Ir Vet $J$ 60: 728-731.

Christopher K, Bruno E 2002. Tested studies for laboratory teaching. Association for Biology Laboratory Education, Louisiana State University 24, p. 103-130.

CLSI/NCCLS - Clinical and Laboratory Standard Institute/National Committee for Clinical Laboratory Standards 2004. Performance standards for antimicrobial disk susceptibility testing. Fourteenth Informational Supplement. Approved standard M100-S14, NCCLS, Wayne, 177 pp.

Corti M, Palmero D, Eiguchi K 2009. Respiratory infections in immunocompromised patients. Curr Opin Pulm Med 15: 209-217.

Ginsburg AS, Grosset JH, Bishai WR 2003. Fluoroquinolones, tuberculosis and resistance. Lancet Infect Dis 3: 432-442.

Goodfellow M, Alderson G 1977. The Actinomycete-genus Rhodococcus: a home for the 'rhodochrous' complex. J Gen Microbiol 100: 99-122.
Heidmann P, Madigan JE, Watson JL 2006. Rhodococcus equi pneumonia: clinical findings. Diagnosis. Treatment and prevention. Clin Tech Equine Pract 5: 203-210.

Holt JG, Krieg NR, Sneath PHA, Staley JT, Willians ST 1994. Bergey's manual of determinative bacteriology, A Waverly Company, Baltimore, $787 \mathrm{pp}$.

Kedlaya I, Ing MB, Wong S 2001. Rhodococcus equi infections in immunocompetent hosts: case report and review. Clin Infect Dis 32: 39-47.

Koneman EW, Allen SD, Janda WM, Schreckenberger PC, Winn WC 2001. Diagnóstico microbiológico: texto e atlas colorido, 5th, Editora Médica e Científica, 1465 pp.

Martin A, Uwizeye C, Fissette K, De Rijk P, Palomino JC, Leão S, Portaels F 2007. Application of the hsp65 PRA method for the rapid identification of mycobacteria isolated from clinical samples in Belgium. J Microbiol Methods 71: 39-43.

Mc Faddin JF 2000. Biochemical tests for identification of medical bacteria, 3th ed., Williams \& Wilkins, Baltimore MD, 901 pp.

McNeil MM, Brown JM 1994. The medically important aerobic actinomycetes: epidemiology and microbiology. Clin Microbiol Rev 7: 357-417.

Meijer WG, Prescott JF 2004. Rhodococcus equi. Vet Res 35: 383-396.

Murray PR, Baron EJ, Pfaller MA, Tenover FC, Yolken HR 1999. Manual of clinical microbiology, 7th ed., ASM Press, Washington DC, p. 1526-1543.

Prescott JF 1991. Rhodococcus equi: an animal and human pathogen. Clin Microbiol Rev 4: 20-34.

Roda RH, Young M, Timpone J, Rosen J 2009. Rhodococcus equi pulmonary-central nervous system syndrome: brain abscess in a patient on high-dose steroids - a case report and review of the literature. Diagn Microbiol Infect Dis 63: 96-99.

Severo LC, Ritter P, Petrillo VF, Dias CAG, Porto NS 2001. Infecção pulmonar por "Rhodococcus equi": relato dos dois primeiros casos brasileiros. J Pneumol 27: 158-162.

Soddell JA, Stainsby FM, Eales KL, Kroppenstedt RM, Seviour RJ, Goodfellow M 2006a. Millisia brevis gen. nov. sp. nov. an actinomycete isolated from activated sludge foam. Int J Syst Evol Microbiol 56: 739-744.

Soddell JA, Stainsby FM, Eales KL, Seviour RJ, Goodfellow M 2006b. Gordonia defluvii sp. nov. an actinomycete isolated from activated sludge foam. Int J Syst Evol Microbiol 56: 2265-2269.

Torres-Tortosa M, Arrizabalaga J, Villanueva JL, Gálvez J, Leyes M, Valencia ME, Flores J, Peña JM, Pérez-Cecilia E, Quereda C 2003. Prognosis and clinical evaluation of infection caused by Rhodococcus equi in HIV-infected patients: a multicenter study of 67 cases. Chest 123: 1970-1976.

Tsitko I, Rahkila R, Priha O, Ali-Vehmas T, Terefework Z, Soini H, Salkinoja-Salonen MS 2006. Isolation and automated ribotyping of Mycobacterium lentiflavum from drinking water distribution system and clinical specimens. FEMS Microbiol Lett 256: 236-243.

von Bargen K, Haas A 2009. Molecular and infection biology of the horse pathogen Rhodococcus equi. FEMS Microbiol Rev 33: 870-891. 